\title{
Вариации физических свойств образцов горных пород (упругая анизотропия, плотность) в рельефе земной поверхности (район г. Домашняя, губа Колвица, Кандалакшский залив)
}

\section{Ильченко В.Л., Сидельникова О.Ф.}

Геологический институт КНЦ РАН, Anamumbl,vadim@geoksc.apatity.ru

Аннотация. По результатам геоморфологического анализа района горы Домашняя сделаны выводы о местных тектонических событиях в недалеком прошлом, а также об их возможном повторении в скором будущем. Для проверки этого предположения проведены исследования физических свойств (плотность, упругая анизотропия) образцов горных пород, отобранных с земной поверхности. Результаты измерений подтверждают выводы более ранних работ аналогичного содержания: для поддержания стабильных условий в поле напряжений горного массива необходимо наличие обратной зависимости между размерами показателя упругой анизотропии образца горной породы и высотой его точки отбора. Сделан вывод о том, что описанный способ оценки физического состояния пород горного склона можно использовать и в других регионах, где существуют проблемы контроля над склоновыми процессами.

Ключевые слова: геоморфологический анализ, образцы горных пород, высота точек отбора образцов, упругая анизотропия, плотность, склоновые процессы.

\section{Variations in the physical properties of rock samples (elastic anisotropy, density) in the relief of the Earth's surface (Domashny mountains, Kolvitsa Bay, Kandalaksha Bay)}

\author{
II'chenko V.L., Sidelnikova O.F. \\ Geological institute KSC RAS, Apatity,fersman@geoksc.apatity.ru
}

\begin{abstract}
Based on the results of a geomorphological analysis of the Domashnaya mountain district, conclusions are made about local tectonic events in the recent past, as well as about their possible recurrence in the near future. To verify this assumption, studies of physical properties (density, elastic anisotropy) of rock samples taken from the surface were carried out. The results of measurement confirm the conclusions of similar earlier studies: to maintain the stability of the stress field of the rock massif, an inverse relationship must exist between the value of the elastic anisotropy index of the rock sample and the height of its sampling point. It is concluded that the described method of estimation of physical condition of a hillside rocks can be used in other regions with problems of control over sidehill processes.
\end{abstract}

Key words: geomorphological analysis, rock samples, height of sampling points, elastic anisotropy, density, sidehill processes.

\section{Введение}

Предварительными исследованиями физических свойств образцов горных пород из коренных выходов на поверхности Печенгского района (Ильченко, 2009) и Центрально-Кольского мегаблока (Ильченко, 2010) установлена обратная зависимость между размером показателя упругой анизотропии породы и высотой ее точки отбора при отсутствии связи этих параметров с плотностью породы. Эта связь имеет очень простое объяснение: размер показателя упругой анизотропии прямо связан с пространственной анизотропией развитой в образце системы микротрещин: то есть, чем выше показатель анизотропии, тем легче порода разрушается под влиянием внешних факторов; при этом плотность породы - параметр очень консервативный и почти не зависит от ее трещиноватости (и анизотропии). Современная трещиноватость поверхностных горных пород обусловлена разгрузкой от литостатических напряжений (по мере удаления вышележащих породных толщ процессом выветривания) или тектоно-кессонным эффектом (Горяинов, Давиденко, 1979).

Главный участок исследований - гора Домашняя (h = 540.5 м, рис. 1) - часть Колвицкого массива, ограниченная грабеном Кандалакшского залива (C3 простирания) и губой Колвица 


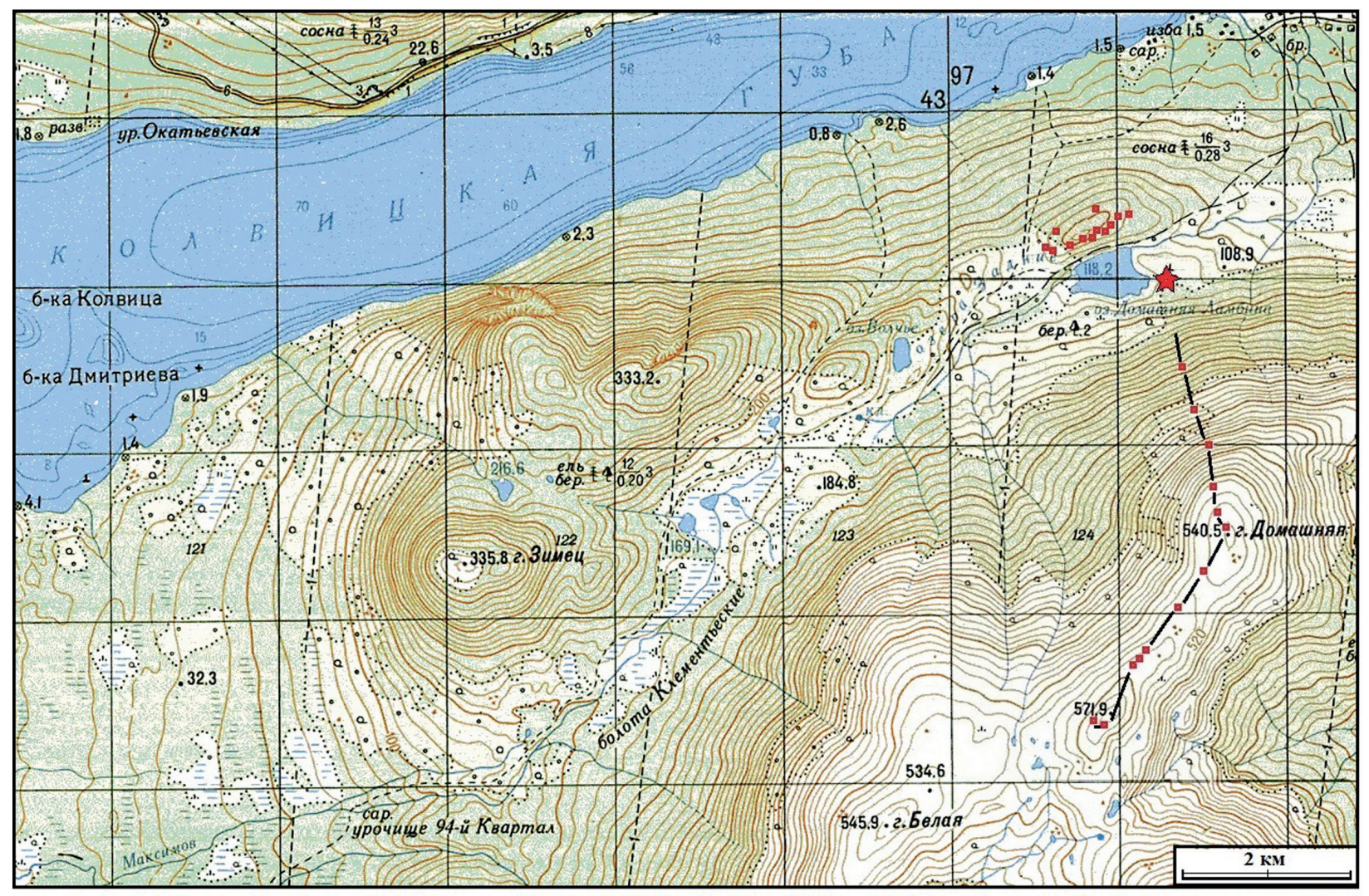

Рис. 1. Топография района исследований. Красные точки - места отбора образцов.

Fig. 1. Topography of the research area. Red dots are sampling locations.

(ВСВ простирания), в составе Белого моря. Южный фрагмент Лапландского гранулитового пояса (ЛГП) - Колвицкий массив - имеет возраст 2.45 млрд. лет (Митрофанов и др., 1993), в его составе амфиболиты, основные гранулиты и габбро-анортозиты; по справочным данным (Физические..., 1988) эти породы имеют высокую плотность и прочность, а значит - могут, под влиянием геодинамических условий, накапливать больше упругой энергии, которая сможет выделиться в момент разрушения этих пород и определит масштаб разрушения. История ЛГП и Белого моря (в т.ч. Кандалакшский грабен, губа Колвица и др.) всегда была тесно связана с формированием Балтийского щита; кайнозойское обновление этих структур продолжается в настоящее время. Тектоническая впадина Кандалакшского залива наследует рифейский грабен, о чем свидетельствуют активные современные опускания авлакогена с возрождением разломов и проявлением вдоль них многочисленных очагов землетрясений (Балуев и др., 2012). Как и многие возвышенности Колвицкого массива, г. Домашняя имеет уплощенную вершину и довольно крутые, а иногда и обрывистые склоны. Такой рельеф обусловливает развитие опасных склоновых процессов (обрушения, оползни, сели и др.), поэтому подобные объекты следует использовать как натуральные полигоны для проведения методических инженерно-геологических изысканий.

\section{Методика исследования и результаты}

Полевые работы в районе горы Домашняя (рис. 1) проведены в августе 2018 г. В ходе геоморфологического анализа района работ (физическая карта), было установлено: горный хребет СВ простирания, в составе 3-х высот: г. Домашняя - т. 571.9 - г. Белая, отделён от губы Колвицкой более низким хребтом (СВ простирания) в составе: г. Зимец, т. 333.2 и два холма (к Ю3 от оз. Волчье и к C от оз. Домашняя Ламбина). Эти хребты разделяет долина (Домашняя Ламбина - болота Клементьевские - ручей Максимов) СВ простирания. Формы хребтов (в плане) имеют сильное сходство, при этом хр. г. Зимец - уменьшенная копия хр. г. Домашняя; выглядит словно ее бывшая верхняя часть - ниже хр. г. Домашняя на $\approx 200$ м, а уровень разделяющей их долины - ниже еще на 150-200 м. 
По результатам анализа можно предположить, что этот ландшафтный ассамбль сформировался в результате тектонической активизации Кандалакшского грабена (сбросо-сдвиг породного массива хр. г. Зимец на С3 - в Колвицкую губу) в период дегляциации Балтийского щита ( $\approx$ 8-10 тыс. лет назад).

Для изучения физических свойств и петрографии отобраны образцы по двум профилям: 1 через массив на С берегу оз. Домашняя Ламбина и 2 - от оз. Домашняя Ламбина - через г. Домашняя - т. 571.9 (всего 26 точек), шаг отбора образцов - произвольный (как позволяла обнаженность коренных пород). Петрография образцов изучена в шлифах.

Для определения физических свойств пород из отобранных штуфов были выпилены образцы кубической формы, после чего их грани были пронумерованы $(1,2,3)$ : направление на грань 3 - вертикаль, направления на грани 1, 2 и 3 взаимно-ортогональны.

Коэффициент анизотропии $A$ для образцов вычислялся из скоростей распространения ультразвуковых продольных волн $\left(V_{1}, V_{2}, V_{3}\right)$, которые были измерены, соответственно, в 3-х направлениях $(1,2,3)$, по формуле:

$$
A=1 / V_{c p} \times\left(\left(V_{1}-V_{\mathrm{cp}}\right)^{2}+\left(V_{2}+V_{\mathrm{cp}}\right)^{2}+\left(V_{3}-V_{\mathrm{cp}}\right)^{2}\right)^{0.5}+100 \%,
$$

где $V_{\text {ср }}=\left(V_{1}+V_{2}+V_{3}\right) / 3$ - средняя скорость распространения продольных волн в образце. Для измерения скорости продольных волн в образцах использован ультразвуковой прибор ГСП УК-10ПМС. Плотность ( $\rho$ ) образцов измерена методом Архимеда. Итоги измерений и вычислений приведены в Таблице, графическое отражение результатов - на рис. 2.

\section{Обсуждение результатов и выводы}

Таблица. Как предполагалось выше, изученная часть Колвицкого массива больше чем наполовину $(\approx 58 \%)$ состоит из пород с повышенной плотностью $\left(2.9-3.2\right.$ г $\left./ \mathrm{cm}^{3}\right)$ и, значит, с повышенной прочностью (и т.д.). При этом встречено много пород с меньшей плотностью (метаанортозиты

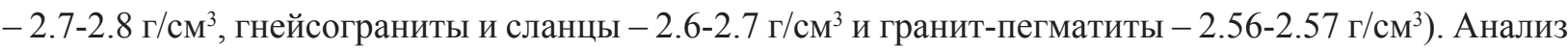
Таблицы снова говорит об отсутствии явной связи между плотностью пород и упругими параметрами (упругая анизотропия, скорость). Самые близкие значения физических свойств имеют образцы микроклиновых пегматитов (№ пп 3 и 23). Хотя и в меньшей мере, но также довольно схожие свойства (близость образцов по $p$ и $V_{p}$ «нарушают» сильные различия в показателях А и т.п.) установлены в метаанортозитах (№ пп 13, 20, 25, 26). Графическое отражение петрофизической ситуации (на рис. 2) снова подтверждает, что самые информативные диагностические параметры напряженного

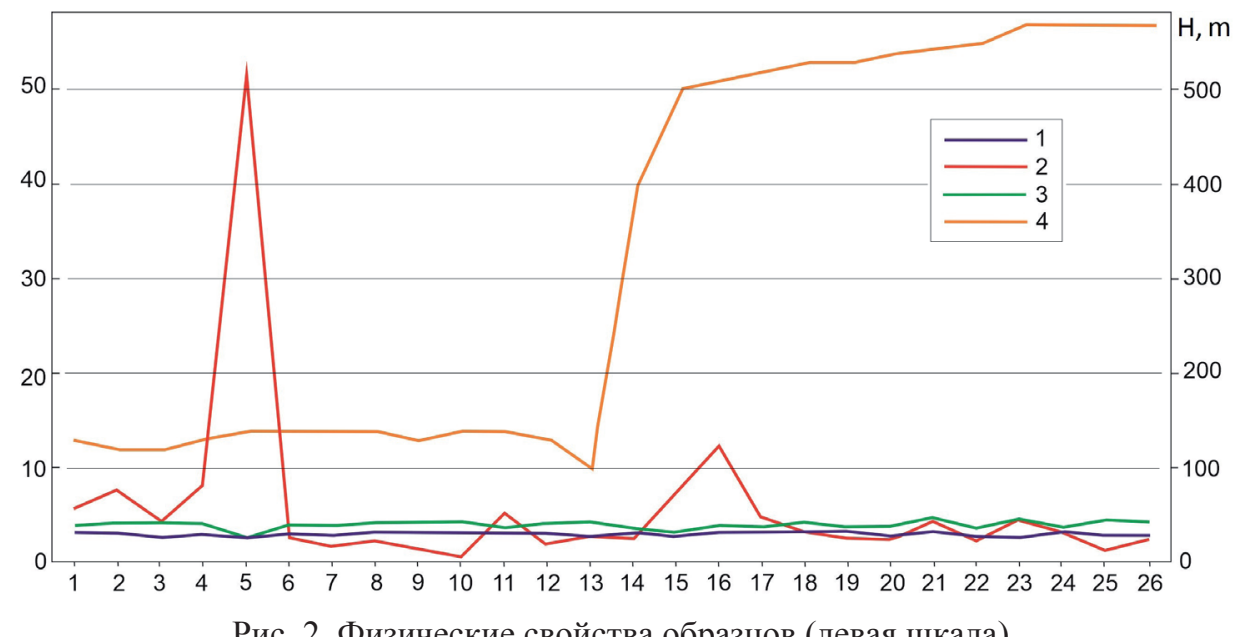

Рис. 2. Физические свойства образцов (левая шкала).

1 - плотность, 2 - показатель упругой анизотропии, 3 - средняя скорость распространения продольных волн $\left(V_{p}\right)$; правая шкала: высота точек отбора образцов; порядок их нумерации: согласно столбцу № 1 в таблице.

Fig. 2. Physical properties of the samples (left scale).

1 - density, 2 - indicator of elastic anisotropy, 3 - average propagation velocity of P-waves $\left(V_{p}\right)$; right scale: height of sampling points; the order of their numbering: according to column $\mathrm{N}^{\circ} 1$ in the table. 
состояния - это показатель упругой анизотропии образца А в паре с высотой его точки отбора Н. Для «спокойных» тектонических условий в массиве необходимо поддержание (от точки к точке по профилю) обратной связи между Н и А, т. е., когда $\mathrm{H}$ - растет, А - сокращается (или наоборот).

Таблица. Физические свойства образцов горных пород и высота их точек отбора.

Table. Physical properties of rock samples and the height of their sampling points.

\begin{tabular}{|c|c|c|c|c|c|c|}
\hline $\begin{array}{l}\text { № } \\
\text { ПП }\end{array}$ & $\begin{array}{c}\text { № } \\
\text { образца }\end{array}$ & $\begin{array}{c}\text { Название породы, структура } \\
\text { (размер зёрен) }\end{array}$ & $\begin{array}{l}\text { Плотность } \\
p\left(\text { г/ } \mathrm{cm}^{3}\right)\end{array}$ & $\begin{array}{l}\text { Скорость }(\text { км/с) } \\
V_{1}, V_{2}, V_{3}, \boldsymbol{V} \boldsymbol{c p .} .\end{array}$ & $\begin{array}{c}\text { Показатель } \\
\text { упругой } \\
\text { анизотропии, } \\
\text { А(\%) }\end{array}$ & $\begin{array}{c}\text { Высота } \\
\text { точки } \\
\text { над уровнем } \\
\text { моря (м) }\end{array}$ \\
\hline 1 & 2 & 3 & 4 & 5 & 6 & 7 \\
\hline 1 & СОФ-3 & $\begin{array}{l}\text { Гранат-плагиоклазовый } \\
\text { амфиболит с-м/3 }\end{array}$ & 3.12 & $\begin{array}{l}3.78 .3 .99 . \\
3.69 .3 .82\end{array}$ & 5.70 & 130 \\
\hline 2 & СОФ-4 & Амфиболит с-м/3 & 3.01 & $\begin{array}{l}3.98 .3 .87 . \\
4.29 .4 .05\end{array}$ & 7.64 & 120 \\
\hline 3 & СОФ-5 & $\begin{array}{l}\text { Пегматит кварц- } \\
\text { микроклиновый }\end{array}$ & 2.57 & $\begin{array}{l}\text { 3.97. } 4.13 \text {. } \\
\text { 4.22. } 4.11\end{array}$ & 4.36 & 120 \\
\hline 4 & СОФ-7 & Плагиоамфиболит с-м/3 & 2.92 & $\begin{array}{l}3.82 .4 .29 . \\
4.08 .4 .06\end{array}$ & 8.20 & 130 \\
\hline 5 & СОФ-8 & Гранитогнейс с-м/3 & 2.63 & $\begin{array}{l}3.02 .3 .24 \\
1.51 .2 .59\end{array}$ & 51.42 & 140 \\
\hline 6 & СОФ-9 & Амфиболит с-м/3 & 2.95 & $\begin{array}{l}4.03 .3 .89 . \\
3.95 .3 .96\end{array}$ & 2.51 & 140 \\
\hline 7 & СОФ-12 & $\begin{array}{l}\text { Гнейсогранит с-м/3, } \\
\text { лейкократовый }\end{array}$ & 2.79 & $\begin{array}{l}3.80 .3 .81 \\
3.88 .3 .83\end{array}$ & 1.61 & 140 \\
\hline 8 & СОФ-13 & Гранатовый амфиболит с-м/з & 3.13 & $\begin{array}{l}4.10 .4 .19 . \\
4.07 .4 .12\end{array}$ & 2.14 & 140 \\
\hline 9 & МАГ-1 & Гранатовый амфиболит с-м/3 & 3.06 & $\begin{array}{l}4.11 .4 .08 . \\
4.16 .4 .12\end{array}$ & 1.39 & 130 \\
\hline 10 & МАГ-4 & Габбродолерит с-м/3 & 3.13 & $\begin{array}{l}4.18 .4 .21 . \\
4.22 .4 .20\end{array}$ & 0.58 & 140 \\
\hline 11 & МАГ-5 & Габброанортозит с-м/з & 2.99 & $\begin{array}{l}\text { 3.47. } 3.73 . \\
3.64 .3 .61\end{array}$ & 5.17 & 140 \\
\hline 12 & МАГ-17a & $\begin{array}{l}\text { Гранатовый амфиболит с-м/3, } \\
\text { хлоритизированн. }\end{array}$ & 2.95 & $\begin{array}{l}3.77 .3 .69 \\
3.78 .3 .75\end{array}$ & 1.87 & 130 \\
\hline 13 & СОФ-30 & $\begin{array}{l}\text { Метаанортозит с-м/3, } \\
\text { амфиболизированный }\end{array}$ & 2.71 & $\begin{array}{l}4.12 .4 .04 \\
3.97 .4 .04\end{array}$ & 2.63 & 100 \\
\hline 14 & МАГ-9 & Амфиболит с-м/3 & 3.07 & $\begin{array}{l}4.27 .4 .13 \\
4.17 .4 .19\end{array}$ & 2.43 & 400 \\
\hline 15 & МАГ-10 & $\begin{array}{l}\text { Сланец м/3, амфибол- кварц- } \\
\text { микроклиновый }\end{array}$ & 2.66 & $\begin{array}{l}3.55 .3 .72 . \\
3.37 .3 .55\end{array}$ & 6.97 & 500 \\
\hline 16 & МАГ-8 & $\begin{array}{l}\text { Метаамфиболит м/3, } \\
\text { плагиоклаз-гранатовый }\end{array}$ & 3.06 & $\begin{array}{l}3.39 .2 .89 \\
3.42 . \mathbf{3 . 2 3}\end{array}$ & 12.30 & 510 \\
\hline 17 & МАГ-11 & $\begin{array}{l}\text { Метапироксенит разно- } \\
\text { зернистый (брекчия?) }\end{array}$ & 3.12 & $\begin{array}{l}3.91 .3 .98 \\
3.73 .3 .87\end{array}$ & 4.71 & 520 \\
\hline 18 & МАГ-7 & Гранатовый амфиболит с-м/з & 3.18 & $\begin{array}{l}3.78 .3 .61 \\
3.71 .3 .70\end{array}$ & 3.26 & 530 \\
\hline 19 & МАГ-13 & Метапироксенит с-м/3 & 3.24 & $\begin{array}{l}\text { 4.27. } 4.20 . \\
3.85 .4 .11\end{array}$ & 2.46 & 530 \\
\hline 20 & МАГ-12 & $\begin{array}{l}\text { Метанортозит, гранат- } \\
\text { амфиболизированный }\end{array}$ & 2.78 & $\begin{array}{l}3.63 .3 .75 \\
3.71 .3 .70\end{array}$ & 2.34 & 540 \\
\hline 21 & МАГ-15 & Амфиболит м/з сланцеватый, & 3.25 & $\begin{array}{l}3.71 .3 .90 . \\
3.70 .3 .77\end{array}$ & 4.23 & 545 \\
\hline 22 & СОФ-23a & $\begin{array}{l}\text { Гранитогнейс амфибол- } \\
\text { микроклиновый с-м/3 }\end{array}$ & 2.68 & $\begin{array}{l}\text { 4.74. } 4.71 \\
\text { 4.60. } \mathbf{4 . 6 8}\end{array}$ & 2.23 & 550 \\
\hline 23 & СОФ-23 & $\begin{array}{l}\text { Микроклин-кварцевый } \\
\text { пегматит, графич.стр. }\end{array}$ & 2.59 & $\begin{array}{l}4.57 .4 .76 . \\
4.47 . \mathbf{4 . 6 0}\end{array}$ & 4.53 & 570 \\
\hline 24 & СОФ-24 & Метапироксенит м/з & 3.19 & $\begin{array}{l}3.65 .3 .56 \\
3.72 .3 .64\end{array}$ & 3.12 & 570 \\
\hline 25 & СОФ-26 & $\begin{array}{l}\text { Метаанортозит с-м/3, } \\
\text { амфиболизированный }\end{array}$ & 2.83 & $\begin{array}{l}4.45 .4 .52 . \\
4.46 . \mathbf{4 . 4 8}\end{array}$ & 1.20 & 570 \\
\hline 26 & МАГ-16 & $\begin{array}{l}\text { Метаанортозит с-м/3, } \\
\text { амфиболизированный }\end{array}$ & 2.84 & $\begin{array}{l}4.20 .4 .29 . \\
4.34 .4 .28\end{array}$ & 2.35 & 570 \\
\hline
\end{tabular}


В нашем случае (рис. 2), на интервале т.т. 1-16 - пологая (нижняя) и крутая (наклонная) части профиля «правильная» обратная связь между высотой точки отбора образца Н и показателем анизотропии А отсутствует. Такое нарушение «правила» означает нарушение равновесия в поле напряжений в данном фрагменте породного массива. На интервале т.т. 14-16 (образцы пород с крутого склона), обратная связь между высотой Н и показателем А также нарушена (параметры Н и А синхронно растут), что предполагает «критическую» ситуацию - частичную нарушенность склоновых пород и их подготовку к разрушению. Далее, с выходом на плато - интервал т.т. 16-26 - «правило обратной связи» вновь начинает работать: по мере роста $\mathrm{H}, \mathrm{A}$ - сокращается, т.е., здесь ситуация в поле напряжений уже вполне равновесная.

Современное обрамление Кандалакшского залива породными массивами с крутыми и высокими склонами создает угрозу обрушения крупных породных масс в залив. Подобное событие может вызвать волну цунами с разрушениями объектов народного хозяйства на побережье. Таким образом, приведённые результаты можно рассматривать как обоснование инженерно-геологических работ вдоль береговой линии Кандалакшского залива в недалеком будущем (их потребность - в условиях глобального потепления когда-нибудь возникнет). По-видимому, описанный способ оценки напряженного состояния пород горного склона можно использовать в регионах, где существуют проблемы контроля над склоновыми процессами.

Работа выполнена в рамках темы НИР ГИ КНЦ РАН: №0226-2019-0052.

\section{Литература}

1. Балуев А.С., Журавлев В.А., Терехов Е.Н., Пржиялговский Е.С. Тектоника Белого моря и прилегающих территорий. (Объяснительная записка к «Тектонической карте Белого моря и прилегающих территорий» м-ба 1:1500000). Отв. ред. Леонов М.Г. / Труды Геологического института. Вып. 597. М. Изд-во: ГЕОС. 2012. 104 с. ISBN 978-5-89118-570-8.

2. Горяинов П.М., Давиденко И.В. Тектоно-кессонный эффект в массивах горных пород и рудных месторождений - важное явление геодинамики // ДАН СССР. 1979. Т. 247. № 5. С. 1212-1215. ISSN 0869-5652.

3. Ильченко В.Л. О результатах изучения анизотропии упругих свойств горных пород из зоны Лучломпольского разлома (Печенгский район, Кольский полуостров) / /Физика Земли. 2009. № 3. С. 64-72. ISSN 0002-3337.

4. Ильченко В.Л. О вариациях плотности и анизотропии упругих свойств архейских пород в приповерхностном залегании (на примере Центрально-Кольского мегаблока, Балтийский щит) // Геоэкология. Инженерная геология. Гидрогеология. Геокриология. 2010. № 1. С. 73-79. ISSN 0869-7803.

5. Митрофанов Ф.П., Балаганский В.В., Балашев Ю.А., Ганнибал Л.Ф., Докучаева В.С., Нерович Л.И., Радченко М.К., Рюнгенен Г.И. U-Рb возраст габбро-анортозитов Кольского полуострова // Докл. РАН. 1993. Т. 331. № 1. С. 95 - 98. ISSN 0869-5652.

6. Физические свойства минералов и горных пород при высоких термодинамических параметрах. Справочник / Под ред. д.ф.-м.н. Воларовича М.П. 2-е изд., перераб. и доп. М. Изд-во: «Недра». 1988. 256 с. 